\title{
Growth and Structural Characterisation of V/Fe Multilayers
}

\author{
A. Marczyńska, J. Skoryna, B. Szymański* and L. Smardz \\ Institute of Molecular Physics, Polish Academy of Sciences, M. Smoluchowskiego 17, 60-179 Poznań, Poland
}

\begin{abstract}
The (110) oriented V/Fe multilayers were prepared at room temperature using UHV magnetron sputtering. As a substrate we have used $\operatorname{Si}(100)$ wafers with an oxidised surface. The surface chemical composition and the cleanness of all layers was checked in situ, immediately after deposition, transferring the samples to an UHV analysis chamber equipped with X-ray photoelectron spectroscopy. The structure of the multilayers has been studied ex situ by low- and high-angle X-ray diffraction. The modulation wavelength was determined from the spacing between satellite peaks in the X-ray diffraction patterns. Results were consistent with the values obtained from total thickness divided by the number of repetitions. Growth of the Fe (V) on $1.6 \mathrm{~nm} \mathrm{~V} \mathrm{(Fe)} \mathrm{underlayer} \mathrm{was}$ studied by succesive deposition and X-ray photoelectron spectroscopy measurements starting from $0.2 \mathrm{~nm}$ of Fe $(\mathrm{V})$ layer, respectively. From the exponential variation of the X-ray photoelectron spectroscopy Fe $2 p$ and V $2 p$ integral intensities with increasing layer thickness we conclude that the Fe and $\mathrm{V}$ sublayers grow homogeneously in the planar mode.
\end{abstract}

DOI: 10.12693 /APhysPolA.127.552

PACS: 75.70.-i, 68.55.-a

\section{Introduction}

Metallic multilayers (MLs) composed of alternating sublayers of ferromagnetic and non-magnetic metals has attracted great interest over the past years because of the successful application of these materials as ultrasensitive hard disc reading heads and magnetic sensors [1, 2]. Furthermore, $\mathrm{V}(001) / \mathrm{Fe}(001)$ MLs were used very recently as a model system to study finite size effect [3]. However, for such MLs only "long period" (0.8-1.0 nm) of antiferromagnetic (AFM) interlayer coupling was found $[4,5]$. The first peak of AFM coupling was observed for vanadium layer thickness between 2 [4] and $2.2 \mathrm{~nm}$ [5] instead expected $d_{\mathrm{V}}=1.2 \mathrm{~nm}$. The above behaviour was explained by magnetic polarisation of $\mathrm{V}$ atoms near $\mathrm{V}-\mathrm{Fe}$ and $\mathrm{Fe}-\mathrm{V}$ interfaces. On the other hand, for nearly perfect $\mathrm{Fe}(100)$ substrates and high quality $\mathrm{Fe} / \mathrm{Cr}$ interfaces, "short period" AFM coupling between Fe(100) films separated by $\mathrm{Cr}$ was observed [6]. Imperfect interfaces, however, can suppress the short period coupling between $\mathrm{Fe}$ layers [6].

In general, the magnetic properties of MLs can be tailored by varying the composition, thickness and microstructure of the magnetic and non-magnetic sublayers. The strength and sign of the interlayer exchange coupling could be tuned by alloying the spacer with nonmagnetic elements [7] or using hydrogen $[8,9]$. In the later case it could be changed not only by electronic structure but also by thickness of the spacer.

For the (001) oriented V/Fe MLs, there is extensive literature on the growth and structural characterisation $[4,5,7-9]$. Much less work has focused on preparation and characterisation of (110) oriented V/Fe MLs. In this paper we report on growth and structure of

${ }^{*}$ corresponding author; e-mail: szyman@ifmpan.poznan.pl
$\mathrm{V}(110) / \mathrm{Fe}(110)$ MLs using in situ X-ray photoelectron spectroscopy (XPS) and ex situ standard $\theta-2 \theta$ X-ray diffraction (XRD), respectively.

\section{Experimental details}

The $\mathrm{V} / \mathrm{Fe}$ multilayers were prepared at room temperature (RT) using computer-controlled ultra high vacuum (UHV) magnetron sputtering [10]. The number of repetitions of the base period was equal to 25 . A capping layer of $5 \mathrm{~nm} \mathrm{Pd}$ was used to allow a fast uptake and release of hydrogen at a temperature of less than $370 \mathrm{~K}$ and to avoid oxidation of the MLs. As a substrate we have used $\operatorname{Si}(100)$ wafers with an oxidised surface to prevent a silicide formation [11]. Therefore we have applied a special heat treatment in UHV before deposition in order to obtain an epitaxial $\mathrm{SiO}_{2}$ surface layer $[11,12]$. The Felayers $\left(0<d_{\mathrm{Fe}}<11 \mathrm{~nm}\right)$ were deposited using a DC source. For preparation of the V-layers $\left(0<d_{\mathrm{v}}<11 \mathrm{~nm}\right)$ an RF source was used. In the case of $\mathrm{V} / \mathrm{Fe}$ MLs a $1.6 \mathrm{~nm} \mathrm{~V}$ buffer layer was first deposited to enhance the (110) growth.

The chemical composition and the cleanness of all layers were checked in situ, immediately after deposition,

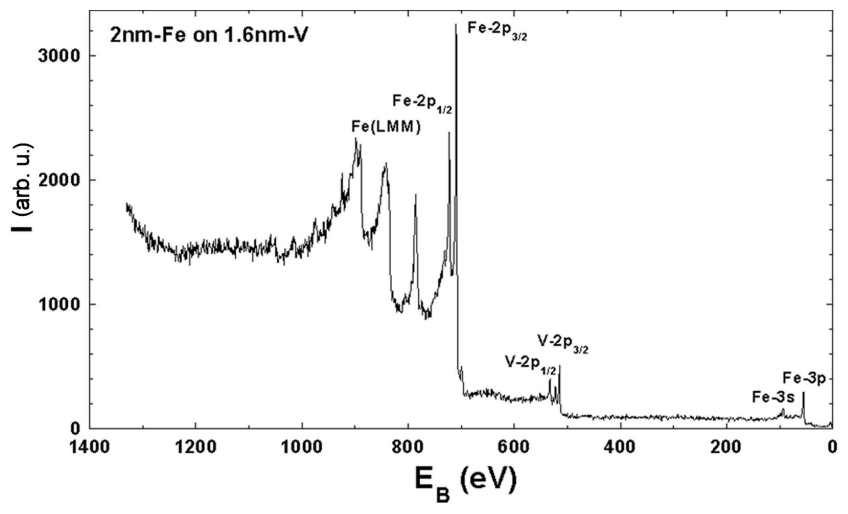

Fig. 1. XPS $\left(\mathrm{Al} \mathrm{K} \mathrm{K}_{\alpha}\right)$ core-level spectrum of freshly deposited $2 \mathrm{~nm}$ Fe layer on $1.6 \mathrm{~nm}$ thick vanadium. 
transferring the samples to an UHV analysis chamber equipped with XPS, Auger electron spectroscopy (AES) and ion gun etching system. The XPS core level spectra were measured with $\mathrm{Al} K_{\alpha}$ radiation at $1486.6 \mathrm{eV}$ at RT using a SPECS EA 10 PLUS energy spectrometer. Details of the XPS measurements can be found in Ref. [13].

The morphology and roughness of the $\mathrm{Pd}$ capping layers were studied ex situ by atomic force microscopy (AFM). The structure of the $\mathrm{V} / \mathrm{Fe}$ MLs was examined ex situ by standard $\theta-2 \theta$ XRD with $\mathrm{Cu} K_{\alpha}$ radiation. The modulation wavelength was determined from the spacing between satellite peaks in the high- and lowangle X-ray diffraction patterns. The thicknesses of individual $\mathrm{Fe}$ and $\mathrm{V}$ sublayers were also determined using $\mathrm{X}$-ray fluorescence analysis (XRF).

\section{Results and discussion}

The chemical composition and the cleanness of all layers were revealed in situ, immediately after deposition, by XPS. In Fig. 1 we show XPS spectrum of $1 \mathrm{~nm} \mathrm{Fe}$ overlayer deposited on $1.6 \mathrm{~nm} \mathrm{~V}$ underlayer. As can be observed in Fig. 1, practically no XPS signals were observed from $\mathrm{O} 1 s$ or $\mathrm{C} 1 s$ and any other potential contaminations.

In the XPS experiment we have also studied the $\mathrm{Fe}$ layer growth on a $1.6 \mathrm{~nm} \mathrm{~V}$ underlayer. The freshly deposited $1.6 \mathrm{~nm} \mathrm{V/d}$ Fe bilayer was in situ transferred from the preparation chamber $\left(5 \times 10^{-10}\right.$ mbar $)$ to the analysis chamber $\left(5 \times 10^{-11}\right.$ mbar $)$, where the XPS Fe $2 p$ and $\mathrm{V} 2 p$ core level spectra were immediately measured in vacuum of $8 \times 10^{-11} \mathrm{mbar}$. Then the bilayer was transferred back to the preparation chamber and the deposition process of the Fe overlayer was continued. The above procedure (overlayer deposition and XPS core level measurements) was repeated until the Fe $2 p_{3 / 2}$ and $\mathrm{V} 2 p_{3 / 2}$ integral intensities were saturated. Practically no trace of oxygen (or any other contaminations) adsorption or surface oxide formation was detected during the transfer operation or XPS measurements $(\approx 10 \mathrm{~min})$.

In Fig. 2 we show XPS core-level spectra measured for Fe $2 p_{3 / 2}$ and Fe $2 p_{1 / 2}$ (Fig. $2 \mathrm{a}$ ), and $\mathrm{V} 2 p_{3 / 2}$ and $\mathrm{V} 2 p_{1 / 2}$ (Fig. 2b) peaks for the $1 \mathrm{~nm}$ Fe layer deposited on $1.6 \mathrm{~nm}$ vanadium underlayer. The positions and the exchange splitting between $2 p_{3 / 2}$ and $2 p_{1 / 2}$ peaks are practically the same compared to those measured for bulk materials.

According to the XPS theory [14] the XPS integral intensities for intense $2 p_{3 / 2}$ peaks of the top Fe $\left(I_{0}\right)$ and bottom $\mathrm{V}\left(I_{s}\right)$ layer for the planar growth are described by

$$
I_{0}=I_{0}^{\infty}\left(1-\mathrm{e}^{-d_{0} / L}\right), \quad I_{s}=I_{s}^{\infty} \mathrm{e}^{-d_{0} / L},
$$

where $d_{0}$ and $L$ denote the overlayer thickness and escape depth of the excited photoelectrons, respectively. After transformations of Eqs. (1), the ideal planar growth of a bilayer system with perfectly sharp interface is represented by a linear equation

$$
\ln \left[\left(I_{s}+I_{0}\right) / I_{s}\right]=d_{0} / L \text {. }
$$

The perfectly planar growth of the model bilayer system [14] is represented by the bold solid line in Fig. 3.

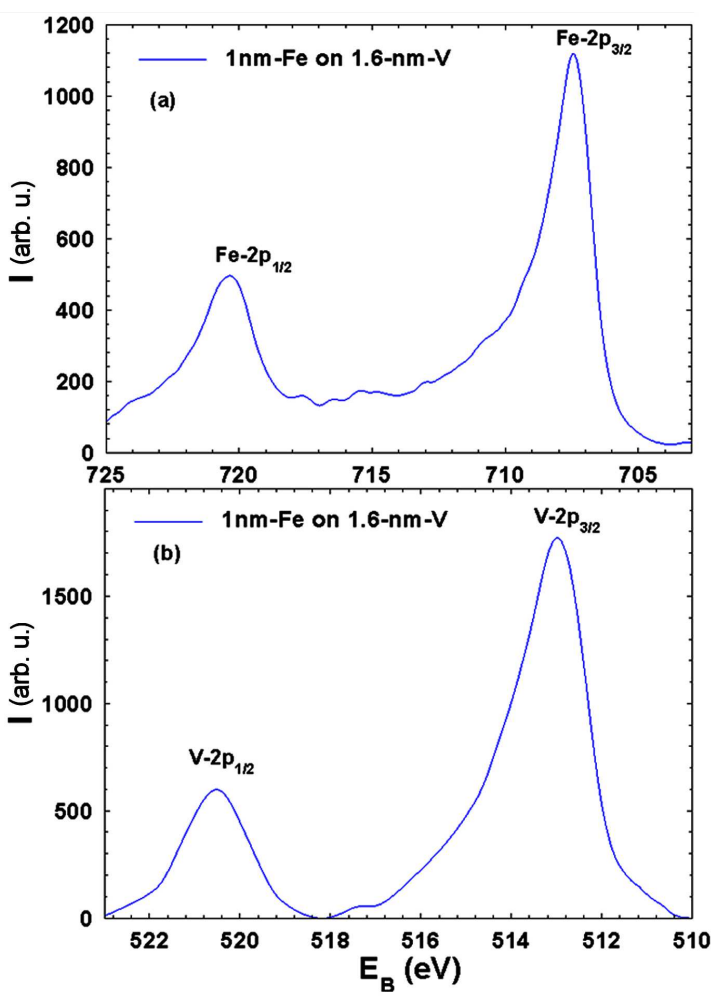

Fig. 2. XPS $\left(\mathrm{Al} \mathrm{K}_{\alpha}\right)$ spectrum of $\mathrm{Fe} 2 p$ (a) and $\mathrm{V} 2 p$ peaks measured for $i n$-situ freshly prepared $1 \mathrm{~nm}$ Fe layer on $1.6 \mathrm{~nm}$ vanadium.

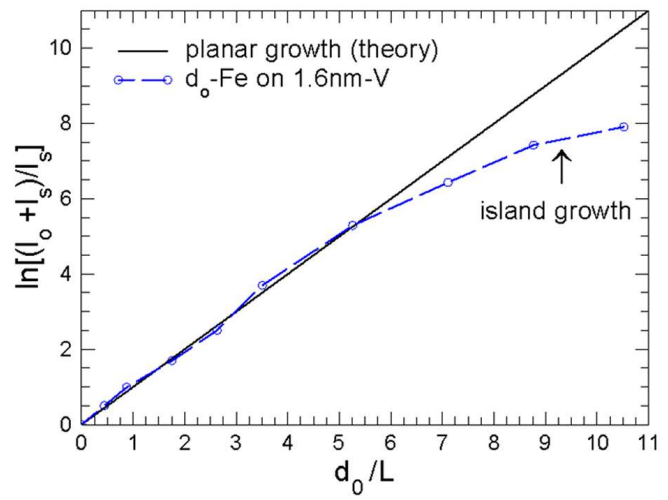

Fig. 3. $\ln \left(\left(I_{S}+I_{0}\right) / I_{S}\right)$ as a function of $d_{0} / L$ (see text). Solid line denotes theoretical (without interface mixing) planar growth of the overlayer [14]. Thin broken lines (open circles connected with broken line) represent linear fit to the experimental data.

Our experimental results (open circles) can be also fitted by linear regressions (see Fig. 3) but only up to Fe layer thickness of about $5 \mathrm{~nm}$, which reveals planar growth (solid line in Fig. 3). For the calculation of the $d_{0} / L$ ratio we have taken escape depth values of $L_{\mathrm{Fe} 2 p}=1.15 \mathrm{~nm}$ and $L_{\mathrm{V} 2 p}=1.3 \mathrm{~nm}$ [14]. The reason for the significantly lower slope of the experimental data shown in Fig. 2 above Fe layer thickness greater than $5 \mathrm{~nm}$ is the island growth during the deposition process $[14-16]$. We have observed very similar behaviour 
during $\mathrm{V}$ growth on $1.6 \mathrm{~nm}$ Fe underlayer. From the exponential variation of the XPS Fe $2 p$ and V $2 p$ integral intensities with increasing overlayer $\mathrm{Fe}(\mathrm{V})$ thickness up to $5 \mathrm{~nm}$ we conclude that the $\mathrm{Fe}$ and $\mathrm{V}$ sublayers grow homogeneously in the planar mode [14]. We have previously observed very similar growth mode for $\mathrm{Fe} / \mathrm{Ti}$ [15] and $\mathrm{Fe} / \mathrm{Zr}[16]$ bilayers.

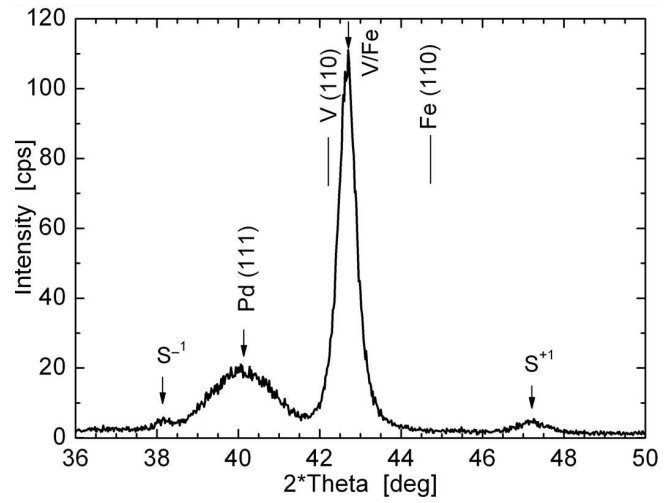

Fig. 4. High-angle $\theta-2 \theta \mathrm{XRD}\left(\mathrm{Cu} \mathrm{K}_{\alpha}\right)$ pattern for the $1 \mathrm{~nm} \mathrm{~V} / 0.6 \mathrm{~nm}$ Fe multilayer.

The structural quality of the multilayers was characterized by high- and low-angle XRD. Figure 4 presents highangle diffraction data taken from multilayered sample of $1 \mathrm{~nm} \mathrm{V/0.6} \mathrm{nm} \mathrm{Fe} \mathrm{having} 25$ bilayer periods. The spectrum shows only diffraction peaks associated with the (110) bcc iron and (110) bcc vanadium planes revealing strong preferential growth in direction perpendicular to the substrate. For all the samples we have observed central Bragg peak (CBP) located between positions expected for reflections of bcc $\mathrm{Fe}(110)$ and bcc V(110) and at least two satellites for the MLs with the thinner sublayers (see Fig. 4). The fitted roughness from the lowangle data was about $0.3-0.4 \mathrm{~nm}$, which is in agreement with AFM measurements [17]. The modulation of composition of the $\mathrm{V} / \mathrm{Fe}$ MLs was also confirmed in the lowangle XRD patterns by intense satellite peaks. The wavelengths of modulation calculated from the high- and lowangle satellite peaks were in good agreement with those values determined from XRF.

In conclusion, the planar growth of the $\mathrm{Fe}$ and $\mathrm{V}$ sublayers was confirmed in situ by XPS measurements. The arifical superstructure and prefered (110) orientation were revealed by XRD experiment.

\section{Acknowledgments}

This work was supported by the National Centre for Research and Development within the project no. POKL.04.03.00-00-015/12.

\section{References}

[1] A. Barthélémy, A. Fert, J-P. Contour, M. Bowen, V. Cros, J.M. De Teresa, A. Hamzic, J.C. Faini, J.M. George, J. Grollier, F. Montaigne, F. Pailloux, F. Petroff, C. Vouille, J. Magn. Magn. Mater. 242245, 68 (2002).

[2] S.A. Wolf, D.D. Awschalom, R.A. Buhrman, J.M. Daughton, S. von Molnár, M.L. Roukes, A.Y. Chtchelkanova, D.M. Freger, Science 294, 1488 (2001).

[3] Xiao Xin, G. Pálsson, M. Wolff, B. Hjörvarsson, Phys. Rev. Lett. 113, 046103 (2014).

[4] M. Ahlberg, E.T. Papaioannou, G. Nowak, B. Hjörvarsson, J. Magn. Magn. Mater. 341, 142 (2013).

[5] M.M. Schwickert, R. Coehoorn, M.A. Tomaz, E. Mayo, D. Lederman, W.L. O'Brien, Tao Lin, G.R. Harp, Phys. Rev. B 57, 13681 (1998-I).

[6] D.T. Pierce, J.A. Stroscio, J. Unguris, R.J. Celotta, Phys. Rev. B 49, 14565 (1994).

[7] B. Skubic, E. Holmström, D. Iusan, O. Bengone, O. Eriksson, R. Brucas, B. Hjörvarsson, V. Stancu, P. Nordblad, Phys. Rev. Lett. 96, 057205 (2006).

[8] F. Klose, Ch. Rehm, D. Nagengast, H. Maletta, A. Weindinger, Phys. Rev. Lett. 78, 1150 (1996).

[9] B. Hjörvarsson, J.A. Dura, P. Isberg, T. Watanabe, T.J. Udovic, G. Andersson, C.F. Majkrzak, Phys. Rev. Lett. 79, 901 (1997).

[10] L. Smardz, Solid State Commun. 112, 693 (1999).

[11] See for example, The Physics and Chemistry of $\mathrm{SiO}_{2}$ and the $\mathrm{Si}_{-} \mathrm{SiO}_{2}$ Interface, Eds. C.R. Helms, B.E. Deal, Plenum, New York 1988.

[12] L. Smardz, U. Köbler, W. Zinn, J. Appl. Phys. 71, 5199 (1992).

[13] L. Smardz, M. Jurczyk, M. Nowak, Int. J. Hydrogen En. 37, 3659 (2012).

[14] D. Briggs, in: Handbook of X-Ray and Ultraviolet Photoelectron Spectroscopy, Ed. D. Briggs, Heyden, London 1977, p. 153.

[15] L. Smardz, K. Smardz, H. Niedoba, Phys. Status Solidi B 243, 227 (2006).

[16] L. Smardz, K. Smardz, Mater. Sci.-Poland 24, 821 (2006).

[17] J. Skoryna, A. Marczyńska, M. Lewandowski, L. Smardz, J. Alloy Comp. in print (2015). 